\title{
Moebius $^{1}$
}

\section{Hernán Toro ${ }^{2}$}

\begin{abstract}
"Leticia Álvarez de Toledo ha observado que la vasta biblioteca es inútil; en rigor bastaría un solo volumen, de formato común, impreso en cuerpo nueve o en cuerpo diez, que constara de un número infinito de hojas infinitamente delgadas. (Cavalieri a principios del siglo XVII, dijo que todo cuerpo sólido es la superposición de un número infinito de planos). El manejo de ese vademécum sedoso no sería cómodo: cada hoja aparente se desdoblaría en otras análogas; la inconcebible hoja central no tendría revés."
\end{abstract}

Jorge Luis Borges. La Biblioteca de Babel.

\section{A}

unque la historia específica que quiero contar ocurrió hace sólo algunas semanas, debo señalar que, con variantes diversas de "modo y lugar", como dicen en su jerga los detestables abogados, me ha ocurrido varias veces a lo largo de mi vida. Para que ella sea bien entendida, quiero anticipar un detalle común a todas esas experiencias de alguna manera repetidas: comienzo del lado de la realidad y, sin saber cómo ni cuándo, termino en la ficción, como si fuera un solo continuum. Como si fuera, no: es un continuum. Es precisamente lo que trataré de mostrar. Ya lo veremos.

${ }^{1}$ Tomado de Cenizas en el puente (2014). Programa Editorial Universidad del Valle, Cali.

${ }^{2}$ Ha publicado 5 libros de cuentos Ajuste de cuentas (Oveja Negra, Bogotá, 1986), A velas abiertas (Mosca Azul editores, Lima, 1990), Las horas cantadas (Universidad del Valle, Cali, 2003), Ceremonias privadas (Universidad del Valle, Cali, 2008) y Cenizas en el puente (Universidad del Valle, Cali, 2014); su cuento El luto del vecindario da título a la colección de cuentos homónima (Ediciones Testimonio, Pasto, 1983). Cuentos suyos han aparecido en 6 libros antológicos. Como investigador ha publicado, aparte de cerca de $\mathbf{5 0}$ artículos en revistas académicas, los siguientes 6 libros de análisis de discursos informativos: La ilusión informativa (1992), Los animales sólo viven en el presente (1997), El reportaje: un género estallado (2003) y La lectura vertical, editados todos por la Universidad del Valle. Es autor, compilador y prologuista del libro El reportaje en Ciudad Vaga (2012) y traductor al español del libro de reportajes Chez les fous (Entre los locos), de Albert Londres (2013), publicados por la Editorial de la Universidad del Valle. 
Todo aconteció en la muy ilustre ciudad de Santa Fe de Bogotá, anacrónica capital del todavía vigente Nuevo Reino de Granada. Me encontraba con una pareja de amigos, casados entre sí, en la Librería del Santo Sepulcro, ubicada en el barrio La Santísima Trinidad, buscando unos libros del gran escritor egipcio Naguib Mahfuz que yo había tenido la ocasión de leer en su lengua original en los lejanos años de mi juventud, cuando ninguna responsabilidad me ataba a esta tierra y nada podía saciar mi curiosidad por otros países, otras culturas y otros idiomas. No habíamos podido ponernos de acuerdo con mi pareja de amigos, ambos amantes de la literatura, acerca de dos títulos cuyas traducciones aproximativas habíamos especulado; buscábamos, pues, las diversas ediciones disponibles en castellano para rastrear en ellas indicios del título original. Entre las vertiginosas hileras de libros sobresalía, como un oasis, una isla, una playa, un espacio despejado en el que se encontraban ordenados un pequeño estrado y una mesa con una jarra de agua y un vaso de cristal vacío, frente a los cuales se desplegaban en abanico una veintena de sillas, ocupadas ya algunas por personas solitarias y taciturnas, todas con aspecto de ser, como dicen los ingleses despectivamente de los profesores universitarios, "Cabezas de huevo" (o, más oralmente, "Cabecehuevos"), que es la traducción certificada de "Egg'heads". Al lado de la tarima, un afiche rústico escrito a mano alzada anunciaba el nombre del expositor, sus títulos nobiliarios y el tema que abordaría. Era evidente que pronto comenzaría una conferencia, pero mi interés y el de mis amigos se centraba en la búsqueda de los libros de Mahfuz. Viéndonos buscar de forma tan acuciosa y evidentemente estéril, una dependiente joven, muy bella, con dos ojos que sólo el temor al ridículo me impide llamar "faros", se acercó a ofrecernos su ayuda. Le explicamos de qué se trataba y nos condujo a anaqueles donde, todos juntos, buscábamos sin encontrar. Para decir la verdad, muy pronto a mí ya no me importó mucho si encontrábamos o no los libros pues me hallaba atrapado en la belleza de los ojos de la dependiente: verdes intensos, 
profundos, esmeraldíferos, un auténtico fruto mineral de las entrañas de mi tierra. No soy joven, ya lo he dicho, pero conservo una inclinación natural hacia la coquetería tan fuerte que será el único bien terrenal que me lleve a la tumba. Yo le hacía preguntas a la dependiente sabiendo de antemano que la respuesta no llegaría, o, si acaso se presentaba, sabía que, como en una inacabable partida de ping pong, ella daría lugar a que el juego se prolongara con nuevas preguntas abiertas y nuevas respuestas sin final. En uno de esos momentos de intercambios inútiles, se me ocurrió preguntarle, mirando significativamente mi reloj, a qué hora comenzaba mi conferencia, haciendo énfasis enérgico sobre el pronombre posesivo. La dependiente arqueó las cejas sobre el abismo de sus ojos de socavón para manifestar su sorpresa mientras mis amigos apenas ahogaron con el dorso de sus manos una sonrisita menor sabiendo que era una broma más entre las centenares de bromas flojas o pesadas que habían tenido que soportarme a lo largo de tantos años de conocimiento recíproco: era el precio que pagaban por mi amistad, pobres. La muchacha miró su reloj.

Muchacha de ojos verdes (sorprendida): A las cinco. ¿Usted es...?

Yo (dándomelas de chistoso): Sí, soy yo.

Muchacha de ojos verdes (confundida): Ah, no sabía. Excúseme.

Yo (fingiendo seriedad): No se preocupe, nadie me conoce. Pero no importa, mejor así.

Muchacha de ojos verdes (recomponiéndose): Pues podemos comenzar cuando usted quiera, ya nos hemos pasado unos minutos. Siquiera que está aquí, ya estaba muy inquieta. Yo tengo que presentarlo.

Yo (falsamente grave, mirando con complicidad a mis amigos para que disfrutaran con mi broma): Ojalá tuviera cinco minutos más, debo preparar mi conferencia.

La dependiente sonrió. "Puede tomárselos, no importa", dijo, haciéndole eco cómplice a mi juego. Y luego agregó, después de gratificarme con un haz de sus... faros: “¿Puedo pedirle que 


\section{HERNÁN TORO}

me firme un libro? No acostumbro, me da vergüenza, pero con usted...quizás...si no le molesta".

Accedí magnánimo y principesco. Ya nos veríamos al final, le prometí malicioso con mi boca llena de sonrisas blancas.

Yo hubiera podido detener allí la payasada y decirle a la muchacha que yo no era Karl Rodríguez Sorensen, filósofo contemporáneo, doctorado en el tema de la Pasión, catedrático de la Universidad de Culiacán, Estado de Sinaloa, que poco o nada sabía del tema anunciado en los afiches que promovían la disertación, y todo habría terminado entonces en un reproche de decepción y en una recriminación sutil de la muchacha. Sin embargo, ¿qué fuerza oculta me dictó el gesto de aquiescencia hacia la muchacha con el cual le indiqué que comenzáramos? ¿Cuál dios maligno me empujó hacia el estrado y me obligó a articular una frase de agradecimiento al público allí presente? ¿Quería yo acaso inconscientemente agradar a mi amiga, por quien siempre guardé una especie de amor inconfesado, con ese gesto atrevido? ¿Deseaba con esa actitud temeraria ganar réditos con la muchacha de los ojos esmeraldíferos por si acaso, uno nunca sabe, la promesa de un fruto prohibido se ofrecía al alcance de mi mano obscena de adulto viejo? No sé nada, nunca he sabido nada: siempre me he sentido en poder de espíritus superiores ante los cuales mis débiles oposiciones no son más que inocuos pataleos de un pobre mortal inerme. El hecho es que, tan pronto agradecí al público su asistencia ya en ese momento unas quince personas ocupaban casi todas las sillas y se acomodaban como si fueran a escuchar una gran revelación-, di disculpas por leer mi conferencia (y no simplemente hablar del asunto con base en algunas notas, que era lo que normalmente hacía) pues la complejidad del tema me obligaba a ser particularmente riguroso. Era claro, dije para justificarme y basado en un viejo recuerdo de mi época de profesor de Semiología en la Universidad de Nariño, en Pasto, Nariño, del lingüista sirio Émile Benveniste (Alepo, Siria, 27 de mayo de 1902 - Paris, Francia, 3 de octubre de 1976), que 
el pensamiento no existía por fuera de la escritura pues en ésta él se sistematizaba ("La escritura funciona como un principio organizador del pensamiento", afirmé, caradura, y aunque no era apócrifo lo de Benveniste -Cf. "De la subjectivité dans le langage in Problèmes de Linguistique Générale, I. Gallimard, Paris, 1966) -, la verdad es que la idea se me había impuesto con convicción a partir de una reciente lectura de Haruki Murakami en la que el escritor japonés expresa más o menos lo mismo (Cf. Autoportrait de l'auteur en coureur de fond. 10/18, Paris, 2009). Y entonces, doctamente, majestuoso, como un pontífice al disponerse a leer el Libro Sagrado, bajé mis ojos hacia las páginas caóticas del libro Nueva antología filosófica. La Pasión (Editorial Tinta Indeleble, Zarzal, Colombia, 1976).

Debo hacer un paréntesis para explicar la presencia de este libro en este momento de la narración. Acostumbro tener en el nochero de mi cama, con el fin de mitigar las devastaciones inmisericordes del insomnio, un montón de libros que, llegado el despertar atrozmente prematuro de cada noche, ojeo un poco al azar; no se trata de adelantar en esos momentos de agonía lecturas atentas sino más bien de fatigar los ojos con un ejercicio visual intenso. Cualquier libro que caiga en mis manos cumple la terapéutica función, y cuando siento la llegada inminente del sueño codiciado, suelto de cualquier manera el ejemplar contra el piso y apago la luz de inmediato, no sea que se escape ese instante de favor divino. La antología, que es uno de esos libros, había terminado por desencuadernarse (¡Ah! ¡Los impresores!), y la baraja casual de sus páginas había terminado por armar una edición caprichosa en la que las hojas se habían organizado a su antojo. ¿Qué hacía yo en mis noches de desvelo? Agarraba el libro desbaratado de filosofía y leía en el orden que el azar había dictado, de tal forma que, por ejemplo, pasaba de la página 148 a la 37, o, dicho de otra manera, hipotéticamente, de un párrafo inconcluso de Heidegger a otro de Sartre apenas iniciado, con lo cual se encadenaban unas lecturas literalmente subrealistas. Como mi 
propósito no era entender (me han dicho que muchos editores trabajan con ese mismo método: comienzan un manuscrito en la página 77 , digamos, leen hasta la 98 , saltan a la 345 , avanzan hasta la 420, vuelven a la 11, y así sucesivamente: ni que se creyeran leyendo una proteica Rayuela) sino cansarme, poco me importaba la corrección metodológica de mi lectura. Ahora bien, el día de la conferencia, por casualidad, había sacado el libro de la casa para llevarlo a encuadernar en uno de los tantos talleres de impresión que pululan por el Santísima Trinidad, barrio de tipógrafos y linotipistas, puro final del siglo XIX, comienzos del XX; de manera que allí estaba el libro, abierto a mis ojos en su enigmática organización fractal.

Antes de leer, consideré conveniente decir, por pura preocupación de impacto, que el asunto de la Pasión venía siendo tratado desde los griegos, pero que ello no le restaba valor y vigencia contemporáneos. Era un tip valioso de erudito que siempre funcionaba. "La Pasión, como decía Spinoza", agregué, después de leer con el rabillo del ojo el exordio de uno de los capítulos del libro, "sucumbe a su conocimiento verdadero", y de inmediato enlacé con un texto del mismo Spinoza, tomado de Ética, que por casualidad apareció de primero bajo mis ojos, cuidándome de no revelar su autoría: “...en virtud de una disposición de la naturaleza humana cada uno apetece que los otros vivan según su propio carácter; en un hombre que no es dirigido por la Razón, este apetito es una pasión llamada Ambición y casi no difiere del Orgullo; al contrario, en un hombre que vive bajo el comando de la Razón, es una acción, es decir, una virtud llamada Moralidad. Y de esta manera todos los apetitos, o Deseos, son pasiones solamente en tanto nacen de ideas inadecuadas; y estos Deseos son tenidos por virtudes cuando son excitados o engendrados por ideas adecuadas". Del texto de Spinoza di un salto de trapecista, en la página que enseguida apareció, a una cita de Soren Kierkegaard, proveniente de Post-Scriptum: "Existir, si no se entiende por ello un simulacro de existencia, no puede hacerse 
sin pasión". Y de inmediato, ágil y flexible, a otra página, con un material de Hegel, extraído de Lecciones sobre la filosofía de la Historia: "La pasión es ante todo el lado subjetivo, en el sentido formal de la energía, de la voluntad y de la actividad; el contenido y el fin permanecen todavía indeterminados; igual ocurre con la convicción personal, con el pensamiento personal, y con la consciencia personal. Se trata siempre del contenido de mi convicción, de la finalidad de mi pasión, de saber si el uno o el otro es verdadero en su naturaleza. Pero inversamente, si él lo es, le corresponde entrar en la existencia, realizarse".

Desde luego, no voy a reproducir en esta historia el contenido exacto de mi charla; he transcrito los fragmentos anteriores con el interés básico de mostrar el tono bajo el cual se desarrolló: cínico, presumido, falsamente sabio. Está claro que la altura del estrado y la posición sentada del público hacían imposible que los asistentes vieran que yo leía hojas de libros y no folios impresos de mi autoría. Multipliqué hasta la náusea el procedimiento, convencido de que todo lo que decía sería verosímil no porque fuera intrínsecamente verdadero sino porque mis palabras se ajustaban estrictamente a las formas protocolarias. Por encima del marco de mis gafas observaba a las personas del público seguir con interés auténtico las frases de mi conferencia, a algunos tomar notas en libretas de periodista, a otros ensimismarse en algún pensamiento que los atrapaba. Esa actitud de interés cierto me entusiasmaba, y pronto comencé a olvidar que yo no era Spinoza, que yo no era Kierkegaard, que yo no era Hegel, que yo no era ninguno de los pensadores de quienes había tomado sus citas inconfesadas. Que tampoco era, por supuesto, Karl Rodríguez Sorensen; pero que mis palabras fuesen seguidas con atención insinuaba que, si no lo era, podía serlo; de hecho, lo estaba siendo. Dicho en otras palabras, no sólo mis oyentes daban por verdadero que yo leía un texto mío sino que creían, sin la menor duda, que yo era el filósofo de la Universidad de Culiacán, Estado de Sinaloa, y, paradoja de paradojas, que ellos así lo creyeran me hacía creer a 


\section{HERNÁN TORO}

mí mismo que yo podía ser cualquiera de los grandes maestros del pensamiento y que, sobre todo, yo estaba siendo Karl Rodríguez Sorensen. Insisto: yo estaba siendo Karl Rodríguez Sorensen. Instalado en esa convicción naciente, continué la lectura de mis textos prestados hasta el final de la disertación, tras lo cual hubo un momento de preguntas del público que yo, Karl Rodríguez Sorensen, filósofo contemporáneo, profesor de la cátedra de Pasión de la Universidad de Culiacán, Estado de Sinaloa, respondía persuadido de la legitimidad de mi saber y la certeza de mi personalidad. No se trataba, para decirlo de manera más precisa y para que no se crea que es una historia traída de los cabellos, que yo hubiera olvidado radicalmente quién era (el retirado exprofesor de Semiología de la Universidad de Nariño, de Pasto, Nariño, visitante en compañía de dos amigos de la Librería del Santo Sepulcro para buscar los títulos en español de dos novelas de Mahfuz), sino que esa personalidad se eclipsaba a favor de la presencia en primer plano de la otra, la del conferencista de Culiacán, Estado de Sinaloa. Si cabe el término, se producía un proceso homólogo al de la fagocitación, en razón del cual mi identidad, si bien era devorada por la del filósofo Rodríguez, algo de ella persistía, sin anularse totalmente: una palpitación, la leve crispación involuntaria de un nervio, un pestañeo.

Al terminar mi ponencia, algunos de los presentes se acercaron a prodigarme comentarios elogiosos o a plantearme alguna duda, y yo les respondí con la sinceridad académica y el respeto ético que se espera de un filósofo: no podía demeritar mi condición intelectual. Tras la lenta disolución del grupo, quedaron sedimentados, como vestigios de la resaca de una experiencia anterior y como avanzada evidente de la realidad, mis dos amigos y la muchacha que me había presentado. Esta, sonriente y expectante, me acercó un libro de mi autoría $-L a$ Pasión según Sartre. Fondo de Cultura Económica. México, D. F. México, 2007-; en la página de guarda escribí: "Con respeto y admiración, Karl Rodríguez Sorensen. Santa Fe de Bogotá, 
Colombia, primavera de 2010". Se lo tendí con gravedad y distancia, y salí. No miré atrás, no quise convertirme en un filósofo de sal. Mis dos amigos me esperaban en la puerta: leían la contratapa de dos ejemplares que sin duda habían comprado y en los que distinguí de inmediato, bien resaltado, en negrillas de 34 puntos, el nombre de su autor: Naguib Mahfuz. Miré el cielo atormentado de las tardes andinas, vi el vuelo plácido de dos gallinazos citadinos cortar el cielo con nitidez, acepté sin remordimiento que esa era la vida en la que me correspondía existir. Entonces entré de nuevo a la realidad con una inclinación de cabeza, que equivalía, ambivalente, a un saludo a mis amigos y a un gesto de sumisión.

Post-Scriptum: ¿Por qué "Moebius", el título que le he dado a esta historia? Esta se sintetizaría eficientemente en la Cinta de Moebius (como se sabe, codescubierta en 1858 por los matemáticos alemanes Ferdinand Mobius -léase moebiusy Johann Benedict Listing). Presumo que muy pocos de mis borrosos lectores saben a qué me refiero. ¿Cinta de Moebius? Diré: es aquella cinta que, tornada sobre su propio eje, permite trazar un recorrido que, sin rupturas, aparentemente comienza afuera y termina adentro. $\mathrm{O}$, de otra manera: agarren por la mitad un ocho en tres dimensiones y gírenlo 180 grados: esa es una cinta de Moebius. Tercera definición: Wikipedia dice que "... es una superficie con una sola cara y un solo borde, o componente de contorno. Para construirla, se toma una cinta de papel y se pegan los extremos dando media vuelta a uno de ellos". Cuarta manera: aquí está la gráfica (A):

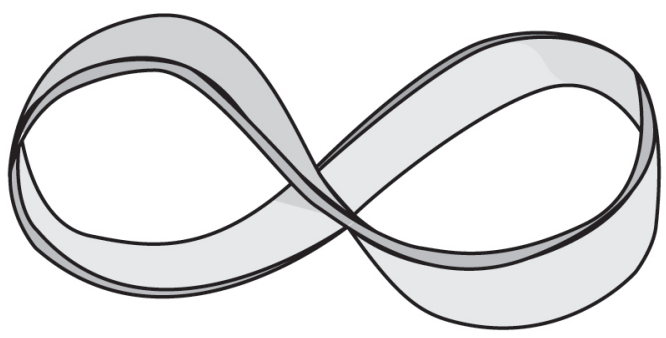




\section{HERNÁN TORO}

Esta es una Cinta de Moebius. Si ustedes inician un recorrido en su parte interna, terminan en la parte externa, como puede verse en la gráfica B:

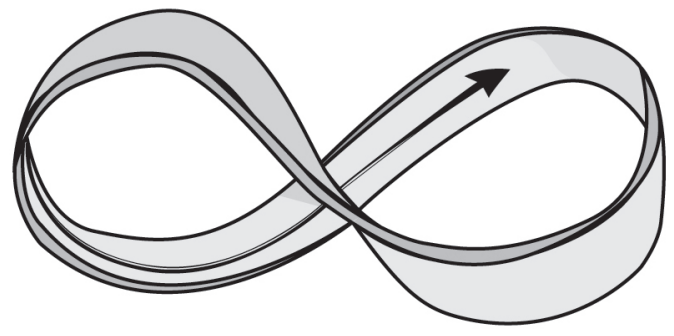

Y si lo inician en el lado exterior, acaban en el interior, según puede verse en la gráfica $\mathrm{C}$ :

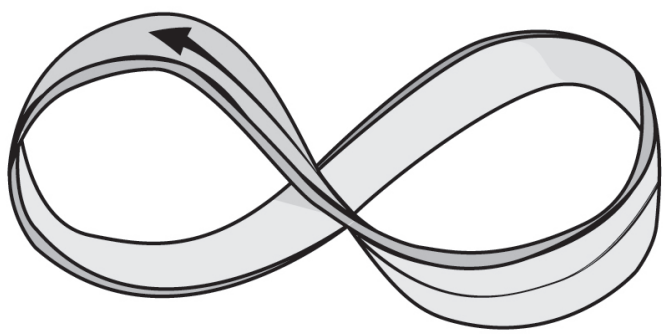

Estas gráficas explican por qué he usado el adverbio "aparentemente" en líneas anteriores en referencia a un lado externo y otro interno: ¡Una superficie de una sola cara! Ya Jorge Luis Borges había hablado de "la inconcebible hoja central (de un libro), que no tendría revés".

Mi historia es un ejemplo en la vida cotidiana de la Cinta de Moebius. 